\title{
Anthrenus (s. str.) pueblanus sp. nov. from Mexico (Coleoptera: Dermestidae: Megatominae)
}

\author{
JIř́ HÁvA \\ Forestry and Game Management Research Institute, \\ Strnady 136, CZ-156 00 Praha 5-Zbraslav, Czech Republic \\ e-mail : jh.dermestidae@volny.cz; https://orcid.org/0000-0001-8076-9538
}

\begin{abstract}
Háva, J.: Anthrenus (s. str.) pueblanus sp. nov. from Mexico (Coleoptera: Dermestidae: Megatominae). Abstract: The species Anthrenus (s. str.) pueblanus sp. nov. from Mexico, Puebla State is described, illustrated and compared with similar species. The new species differs in the structure of antennae and male genitalia. A key to the Nearctic species of Anthrenus Geoffroy is presented.
\end{abstract}

Keywords: taxonomy, new species, key, description, Coleoptera, Dermestidae, Megatominae, Anthrenus, Mexico.

\section{Introduction}

The genus Anthrenus Geoffroy, 1762 currently includes approximately 240 species worldwide (Háva 2020) including the new species described herein. Nineteen species have been recorded from Canada, the United States and Mexico (KADEJ 2011, Háva 2015, 2020). The last general revision of Nearctic species of the genus Anthrenus was published by BeAL (1998) and comprised taxonomic studies, an overview of the biological, ecological, and economic importance of the genus, and descriptions of five new species. Next and last new species was described by KADEJ (2011) from California. In the present paper, a new species of the nominotypical subgenus Anthrenus is described from Puebla, Mexico.

\section{Material and methods}

The size of the beetles or of their body parts can be useful in species recognition and thus, the following measurements were made:

total length (TL) - linear distance from anterior margin of pronotum to apex of elytra;

elytral width (EW) - maximum linear transverse distance.

Deposition of type material:

JHAC - Jiří Háva, Private Entomological Laboratory \& Collection, Únětice u Prahy, Prague-West, Czech Republic.

The nomenclature and zoogeography follow HÁva (2015). 
All the colour photographs were taken by a Nikon Coolpix 990 digital camera through an MBS-10 binocular stereo microscope and 3D Microscope with Full HD Camera.

The specimen of the presently described species is provided with a red, printed label with texts as follows: „HOLOTYPE Anthrenus (s. str.) pueblanus sp. nov. J. Háva det. $2021 ”$.

\section{Results}

Anthrenus (s. str.) pueblanus sp. nov. (Figs. 1-4)

Type material: Holotype (ð): „Cacaloapan, Pue. [Puebla], ca. 5500 ft.alt., iii:9:[19]48, MEX. [Mexico]“, (JHAC).

Description: Male: Body convex, slightly rounded laterally; measurements: TL 2.1 $\mathrm{mm}$, EW $1.5 \mathrm{~mm}$. Body covered with oval-subtriangular scales.

Head visible from above; eyes large, convex, with internal, medial deep and broad emargination, with intermixed white, orange and brown scales. Median ocellus present. Clypeus emarginate. Labrum light brown, entirely with short tan setae on the dorsal surface. Antenna with 11 antennomeres, antennal club dark brown, composed of 3 antennomeres (Fig. 2). Antennal fossa conforming to shape of antennal club. Dorsal and ventral surfaces of integument dark-brown, almost black, sparsely punctured, covered by scales (Fig. 1).

Pronotum covered by intermixed white and orange scales, and brown scales forming patches. Lateral margin of pronotum dilated above antennal fossa and visible from above.

Scutellum small and poorly marked, without scales.

Elytra covered by white, orange and brown scales. The scales are abraded on most of the elytra, white and brown scales forming spots. Humeri with large bump. Individual scales more or less triangular with apex of body of scale truncate and lapped arcuate.

Ventral surface with white scales. Brown and yellow scales cover posterior margin of ventrites II-V, middle section of ventrite V only white; ventrites I-V sometimes entirely white; first abdominal ventrite with post-coxal lines, sulcus without scales. Abdominal ventrites as in Fig. 3.

Pygidium black with sub-basal, transverse, carina-like line with adjacent setae; light brown setae limited to apical area.

Legs dark-brown and covered with white scales and black setae on dorsal surface. Tibiae without distinct teeth (tibial spines). Tarsus with two slightly curved claws.

Male aedeagus as in Fig. 4.

Female: Unknown.

Differential diagnosis: The new species is externally similar to A. maculatus Fabricius, 1798 (= parvus Casey, 1900, acomanus Casey, 1916) and A. umbra Beal, 1998, but differs from them by the structure of antennae and male genitalia; from other Nearctic species it differs by the characters shown in the following modified key. 

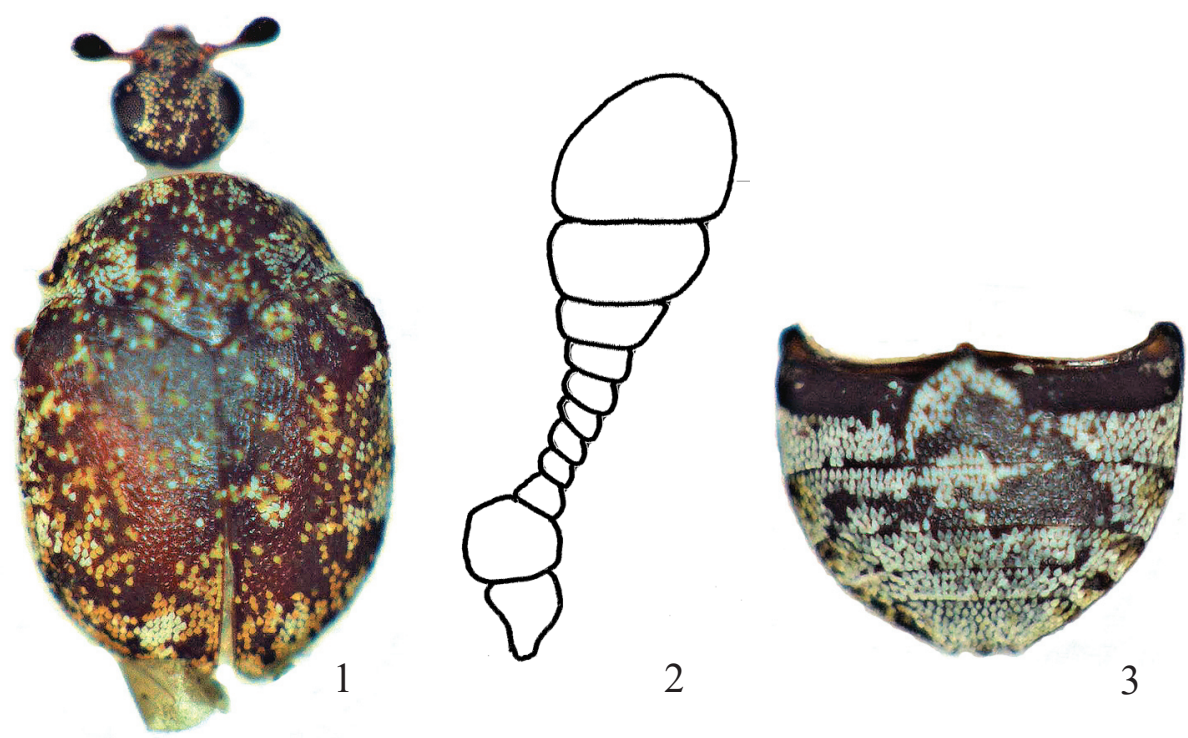

Figs. 1-3: Anthrenus (s. str.) pueblanus sp. nov.:

1- habitus dorsal, 2- antenna of male, 3- abdomen

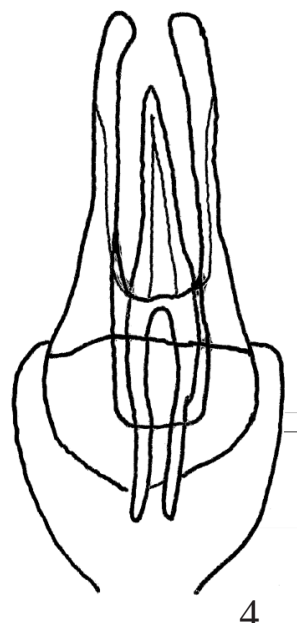

4

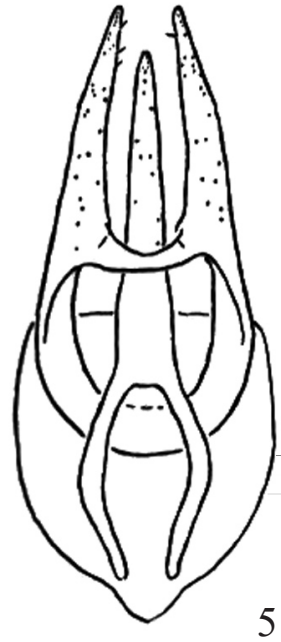

5

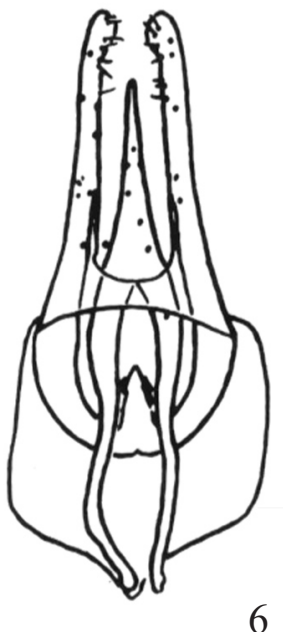

6

Figs. 4-6: Aedeagus: 4- A. pueblanus sp. nov., 5- A. maculatus Fabricius, 1798, 6- $A$. umbra Beal, 1998 (according to BEAL 1998)

Etymology: Named after the type locality Puebla State, Mexico.

Distribution: The species is described from Mexico: Puebla. 
Key to the Nearctic species of Anthrenus Geoffroy (modified key from KADEJ 2011)

1. Antenna with 8-11 antennomeres

1 '. Antenna with 5 antennomeres. A. fuscus

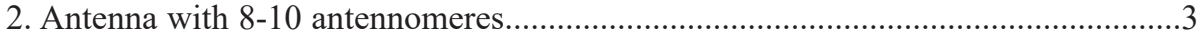

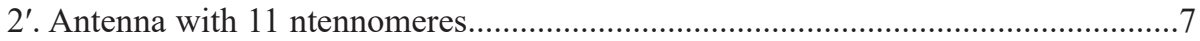

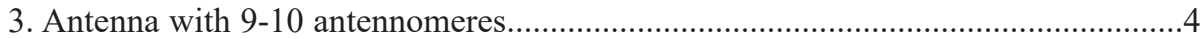

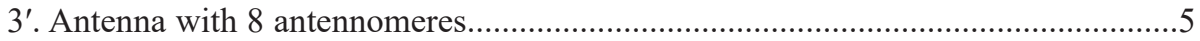

4. Antenna with 9 antennomeres, antennal club with two antennomeres, male antennomere 9 at least $4 \mathrm{X}$ longer than antennomere 8.

A. coloratus

$4^{\prime}$. Antenna with 10 antennomeres, antennal club with three antennomeres.... A. omoi

5. Male antennomere 8 less than $5 X$ longer than antennomere 7.

5 . Male antennomere 8 at least $5 \mathrm{X}$ longer than antennomere 7.

A. museorum

6. Elytron with crescent-shaped subbasal band of pale scales prominent, wider than submedian band....

$6^{\prime}$. Elytron with subbasal crescent of pale scales usually thin and less prominent than submedian band

A. castaneae

7. Eye with median margin complete, scales short and wide, 1.5-2.0X as long as wide

7'. Eye without median margin entire (oval), scales elongate, very narrow (seta-like), 3-6X as long as wide

A. verbasci

8. Elytron with 1 broad, white band covering half or nearly all of elytron, or with 3 transverse bands.

$8^{\prime}$. Elytron entirely white except for small patch of dark scales on humerus and occasionally a small, submedian patch of yellowish or brownish scales.

9. Elytron with clearly distinguishable pattern of bands or lines.

A. umbra

9'. Elytron without clearly distinguishable pattern of bands or lines; patterns irregular......

10. More than 1 (often discontinuous) band of white scales transverse.

$10^{\prime}$. One transverse and continuous band of white scales distinguishable. 15

11. White transverse band wide. 11

$11^{\prime}$. White, transverse band narrow. Elytron with subbasal band of white scales much shorter at suture than at lateral margin

12. White transverse band well-defined. A. pimpinellae

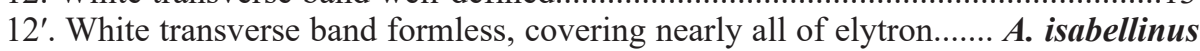

13. White, funnel-shaped band reaching apex of elytron near suture. Pronotum with black and brown scales intermixed with small white scales A. sophonisba

13'. White band covering more than half of elytron. Black scales in apical part of elytron present. Pronotum with numerous white scales arranged in patches surrounded by brown and black scales.

A. chiton

14. Dark brown scales cover posterior margin of ventrites I-V and middle section of ventrite $\mathrm{V}$

A. fucosus

$14^{\prime}$. A(B) Brown scales cover posterior margin of ventrites II-V and middle section of ventrite V; sometimes ventrites I-V entirely white, aedeagus (Fig. 5) ....... A. maculatus

$\mathrm{B}(\mathrm{A})$ Brown and yellow scales cover posterior margin of ventrites II-V, middle section of ventrite $\mathrm{V}$ only white; sometimes ventrites I-V entirely white, aedeagus (Fig. 4) ......

15. Elytron with sutural line of red scales extending from scutellum to apex.

$15^{\prime}$. Elytron without sutural line of red scales extending from scutellum to apex.....17 
16. Elytron with lateral subbasal, submedian, and subapical patches of white scales distinct, neither meeting sutural line of red scales nor connected with sutural red scales by interrupted bands A. scrophulariae

16'. Elytron with subbasal and submedian bands of white scales clearly meeting sutural line of red scales A. thoracicus

17. Elytron with continuous subbasal band of white scales .18

$17^{\prime}$. Elytron without continuous subbasal band of white scales. A. lepidus

18. Ventrites I-V clothed only with white scales A. pulaskii

18'. Ventrites I-V clothed with white and light brown scales; light brown scales cover posterior margin of ventrites $\mathrm{I}-\mathrm{V}$ and middle section of ventrite $\mathrm{V}$. A. flavipes

\section{Acknowledgements}

I am indebted very much to Miloslav Rakovič (Czech Republic) for a revision of the English manuscript. The paper was supported by the Ministry of Agriculture of the Czech Republic, institutional support MZE-RO0118.

\section{References}

BeAL, R. S. 1998: Taxonomy and Biology of Nearctic Species of Anthrenus (Coleoptera: Dermestidae). Transactions of the American Entomological Society 124: 271-332.

Háva, J. 2015: World Catalogue of Insects. Volume 13. Dermestidae (Coleoptera). Leiden/Boston: Brill, xxvi $+419 \mathrm{pp}$.

Háva, J. 2020: Dermestidae World (Coleoptera). - World Wide Web electronic publication (open in 2004): http://www.dermestidae.wz.cz (version 2018, update January 2020)

KADEJ, M. 2011: A new species of Anthrenus Geoffroy, 1762 (Coleoptera: Dermestidae) from California, with a key to the Nearctic species. - The Coleopterists Bulletin 65: 309-314. https://doi. org/10.1649/072.065.0314 
